V.S. Grinchenko, K.V. Chunikhin, N.V. Grinchenko

\title{
LOW-FREQUENCY MAGNETIC FIELD SHIELDING BY A CIRCULAR PASSIVE LOOP AND CLOSED SHELLS
}

Purpose. To analyze the shielding factors for a circular passive loop and conductive closed shells placed in a homogeneous lowfrequency magnetic field. Methodology. We have obtained simplified expressions for the shielding factors for a circular passive loop and a thin spherical shell. In addition, we have developed the numerical model of a thin cubical shell in a magnetic field, which allows exploring its shielding characteristics. Results. We have obtained dependences of the shielding factors for passive loops and shells on the frequency of the external field. Analytically determined frequency of the external magnetic field, below which field shielding of a passive loop is expedient to use, above which it is advisable to use a shielding shell. References 10 , figures 4. Key words: shielding factor, magnetic field, circular passive loop, thin shell.

Проведен сравнительный анализ эффективности экранирования однородного низкочастотного магнитного поля электропроводящим кольцом и замкнутыми оболочками. Получены упрощенные выражения для эффективности экранирования магнитного поля электропроводящим кольцом и тонкостенной сферической оболочкой. Разработана численная модель тонкостенной кубической оболочки в магнитном поле, позволяющая исследовать её экранирующие характеристики. Приведены зависимости эффективности экранирования кольцом и замкнутыми оболочками от частоты внешнего поля. Аналитически определена частота внешнего магнитного поля, ниже которой для экранирования поля целесообразно использовать электропроводящее кольцо, выще которой целесообразно использовать замкнутую оболочку. Библ. 10, рис. 4.

Ключевые слова: эффективность экранирования, магнитное поле, электропроводящее кольцо, тонкостенная оболочка.

Introduction. Negative effect of the magnetic field (MF), in particular the low-frequency magnetic field, on the human health [1] as well as limitations on levels of MF in which the stable operation of modern equipment is guaranteed [2] require reducing values of magnetic flux density to accepted ones.

Let's consider a problem of the homogeneous lowfrequency MF mitigation in a local domain. Shielding systems are divided into passive and active by the way of power supply. In some works $[3,4]$ there is proposed to use systems of active shielding for the MF mitigation in the local domain. However, in this work the consideration will be limited by passive electromagnetic shielding. To reduce the external MF in the local domain the electromagnetic shields are manufactured as thin closed shells and usually they have shape of a box or a cylinder with equipment located inside them [5-9]. In [9] there was proposed to use a circular passive loop for the low-frequency MF shielding. In [10] an expression for the shielding factor was written more exactly, and radius of the domain within the circular passive loop in which it is recommended to place equipment was determined.

The goal of this work is to compare shielding properties of the circular passive loop (see Fig. 1,a) and thin closed shells (see Fig. 1,b,c) at various frequencies of the external MF as well as to determine a criterion of utilization of one or another shielding element.
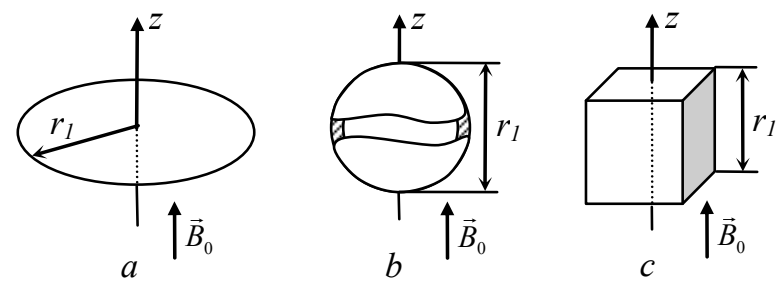

Fig. 1

At the analysis shells of cubic and spherical shapes are considered. A shielding shell has the spherical shape seldom but frequently closed shields of various shape can be approximately substituted by a spherical shield of the equivalent volume in such a way that three coordinate dimensions of the substituted shield approach to the diameter of spherical one [5].

The MF shielding by a circular passive loop. Shielding factor $S F$ is the ratio of the RMS value of the external magnetic flux density to the RMS value of the magnetic flux density at the utilization of the shield. Let's assume that a circular passive loop of the radius $r_{1}$ with a round cross-section of the radius $r_{2}$ is placed in the homogeneous low-frequency MF (see Fig. 1,a). The loop's plane is oriented perpendicular to the external MF, and the magnetic flux density complex amplitude is $\dot{\vec{B}}_{0}=\vec{e}_{z} \cdot B_{0}$, where $B_{0}$ is the external MF amplitude, $\vec{e}_{z}$ is the ort. The frequency of the external MF is $f, \mathrm{~Hz}$. Then, the shielding factor for the circular passive loop $[10]$ in the sighting point $(r, z)$ equals to

$$
S F=\frac{B_{0}}{\sqrt{\left|B_{0}+\dot{B}_{z}^{\text {coil }}\right|^{2}+\left|\dot{B}_{r}^{\text {coil }}\right|^{2}}},
$$

where

$$
\begin{gathered}
\dot{B}_{z}^{\text {coil }}=\frac{\mu_{0} \dot{I}}{2 \pi \sqrt{\left(r_{1}+r\right)^{2}+z^{2}}} \cdot\left[\frac{r_{1}^{2}-r^{2}-z^{2}}{\left(r_{1}-r\right)^{2}+z^{2}} \cdot E(k)+K(k)\right], \\
\dot{B}_{r}^{\text {coil }}=\frac{\mu_{0} \dot{I} z}{2 \pi r \sqrt{\left(r_{1}+r\right)^{2}+z^{2}}} \cdot\left[\frac{r_{1}^{2}+r^{2}+z^{2}}{\left(r_{1}-r\right)^{2}+z^{2}} \cdot E(k)-K(k)\right],
\end{gathered}
$$

are components of MF created by the inducted in the passive loop current; the complex amplitude of the current is

$$
\dot{I}=\frac{\pi}{\mu_{0}} \cdot \frac{r_{1} B_{0}}{\frac{7}{4}-\ln \frac{8 r_{1}}{r_{2}}+j \cdot \frac{1}{\mu_{0} \pi f \sigma r_{2}^{2}}} ;
$$

(C) V.S. Grinchenko, K.V. Chunikhin, N.V. Grinchenko 


$$
K(k)=\int_{0}^{\pi / 2} \frac{d \varphi}{\sqrt{1-k^{2} \sin ^{2} \varphi}}, E(k)=\int_{0}^{\pi / 2} \sqrt{1-k^{2} \sin ^{2} \varphi} d \varphi,
$$

are complete elliptic integrals of the $1^{\text {st }}$ and the $2^{\text {nd }}$ kind, respectively; $k=\sqrt{\frac{4 r_{1} r}{\left(r_{1}+r\right)^{2}+z^{2}}}$ is the numerical coefficient; $\sigma$ is the loop's conductivity, $\mathrm{S} / \mathrm{m} ; \mu_{0}=4 \pi \cdot 10^{-7} \mathrm{H} / \mathrm{m}$ is the magnetic constant; $j$ is the imaginary unit.

As it was shown in [10], if $r_{1}$ is the passive loop radius then it is useful to limit the shielding domain located in its central part by a sphere of radius $r_{1} / 2$. The shielding factor $S F$ is a function of the sighting point coordinates. Minimal $S F$ takes places on the shielding domain's bound on the circular loop's axis: $S F_{\text {coil }}=S F\left(r=0, z=\frac{r_{1}}{2}\right)$. Using (1) we obtain the final expression for the circular passive loop's shielding factor:

$$
S F_{\text {coil }}=\left[1+\frac{\frac{16 \pi^{2}}{125}+\frac{8 \pi}{5 \sqrt{5}}\left(\frac{7}{4}-\ln \frac{8 r_{1}}{r_{2}}\right)}{\left(\frac{7}{4}-\ln \frac{8 r_{1}}{r_{2}}\right)^{2}+\left(\frac{1}{\mu_{0} \pi f \sigma r_{2}^{2}}\right)^{2}}\right]^{-1 / 2} .
$$

The MF shielding by a conductive spherical shell. A problem of the MF determination within a thin conductive spherical shell placed in the homogeneous lowfrequency MF (see Fig. 1,b) is considered in [5]. In this work the calculation of the shielded MF is carried out at the following assumptions. Firstly, the shell thickness $d_{s}$ is supposed to be much less than the MF penetration depth to the conductor $\delta$. Secondly, the thickness $d_{s}$ is supposed to be much less than the shell radius $R$. At these assumptions the MF within the shell is homogeneous, and the shielding factor equals to

$$
S F_{\text {sphere }}^{(\text {Kaden })}=\left|\operatorname{ch~} k d_{s}+\frac{1}{3} \cdot\left(K+\frac{2}{K}\right) \cdot \operatorname{sh} k d_{s}\right|,
$$

where $K=k R$ and $k=\sqrt{j \mu_{0} 2 \pi f \sigma+\frac{2}{R^{2}}}$ are the nondimensional coefficient and the coefficient with dimensionality $\mathrm{m}^{-1}$, respectively; $\sigma$ is the spherical shell conductivity, $\mathrm{S} / \mathrm{m}$. In (3) the spherical shell relative permeability is assumed to be equal 1 .

For the considered in the present work dimensions and frequencies the following relation takes place: $\delta<<R$. Considering the expansion of the second member of (3) by the small parameter $\delta / R$, we obtain the expression for the shielding factor for the conductive spherical shell placed in the homogeneous low-frequency MF:

$$
S F_{\text {sphere }}=\sqrt{1+\left(\frac{\mu_{0} 2 \pi f \sigma R d_{s}}{3}\right)^{2}} .
$$

The MF shielding by a conductive cubic shell. Analytical calculation of the MF within a conductive cubic shell placed in the external MF (see Fig. 1,c) is very difficult. Therefore, it is useful to use the numerical modeling. Because of the exciting field is low-frequency, the $\mathrm{MF}$ is described by the equation obtained from the Am- pere's circuital law in quasi-static approach:

$$
\left\{\begin{array}{l}
\Delta \dot{\vec{A}}^{(i)}=-j \mu_{0} 2 \pi f \sigma \dot{\vec{A}}^{(i)}, \\
\Delta \dot{\vec{A}}^{(e)}=0
\end{array}\right.
$$

where $\dot{\vec{A}}^{(i)}, \dot{\vec{A}}^{(e)}$ are complex amplitudes of the vector potential of the electromagnetic field inside and outside the cubic shell's walls, respectively; $\sigma$ is its conductivity, $\mathrm{S} / \mathrm{m}$. In (5) the cubic shell relative permeability is assumed to be equal 1 .

To «link» solutions of the system (5) it is necessary to set conditions on the interface of the air region and conductive shell's walls:

$$
\left\{\begin{array}{l}
\dot{A}_{\tau}^{(i)}=\dot{A}_{\tau}^{(e)}, \\
\left(\operatorname{rot} \dot{\vec{A}}^{(i)}\right)_{\tau}=\left(\operatorname{rot} \dot{\vec{A}}^{(e)}\right)_{\tau},
\end{array}\right.
$$

where the index $\tau$ indicates that tangential for the interface vectors components are taken.

On the calculation region's bound the MF is supposed to be undisturbed, and the magnetic potential is set to equal to

$$
\left\{\begin{array}{l}
\dot{A}_{x}=-y \cdot B_{0} / 2, \\
\dot{A}_{y}=x \cdot B_{0} / 2, \\
\dot{A}_{z}=0,
\end{array}\right.
$$

where $x, y$ are coordinates of the point on the calculation region's bound. For the correct utilization of (7), the calculation region's dimension is selected much more that the cubic shell edge.

The described problem is solved by the Finite Element Method using the software package COMSOL Multiphysics. To solve the problem, the interface «Magnetic Fields» which is a part of the «AC/DC Module» was used. This interface permits to model processes described by the equations (5). Building the 3D model for the option «Space Dimension», the variant «3D» was set. In all domains the mesh «Free Tetrahedral» was used, and within the cubic shell walls the mesh was finest.

Input parameters of the model are the amplitude $B_{0}$ and the frequency $f$ of the external MF, the conductivity $\sigma$, the edge length $a$, and the walls thickness $d_{c}$ of the cubic shell. The calculation result is the distribution of the RMS value of the magnetic flux density $B_{r m s}(x, y, z)$.

The cubic shell placed in the homogeneous MF $\dot{\vec{B}}_{0}=\vec{e}_{z} \cdot B_{0}$ is shown in Fig. 2. The MF frequency is equal to $150 \mathrm{~Hz}$. The borders of the cubic shell are shown by a dashed line. The shell is made of copper, the edge length is equal to $0.3 \mathrm{~m}$, and the wall thickness is equal to $0.27 \mathrm{~mm}$. The isolines in the Fig. 2 correspond to values of $S F^{-1}(x, y, z)=\frac{B_{r m s}(x, y, z)}{B_{0} / \sqrt{2}}$ from 0.8 to 1.05 . The distribution is built in the plane $y=0$. In the center of the shell under consideration $S F^{-1}=0.81$. Hence, the variation of $S F^{-1}$ within the shell is less than $1 \%$. Therefore, the shielding factor for the cubic shell is determined as

$$
S F_{\text {cube }}=\min \left\{\frac{B_{0} / \sqrt{2}}{B_{r m s}(x, y, z)} \mid \sqrt{x^{2}+y^{2}+z^{2}}<\frac{a}{3}\right\} .
$$




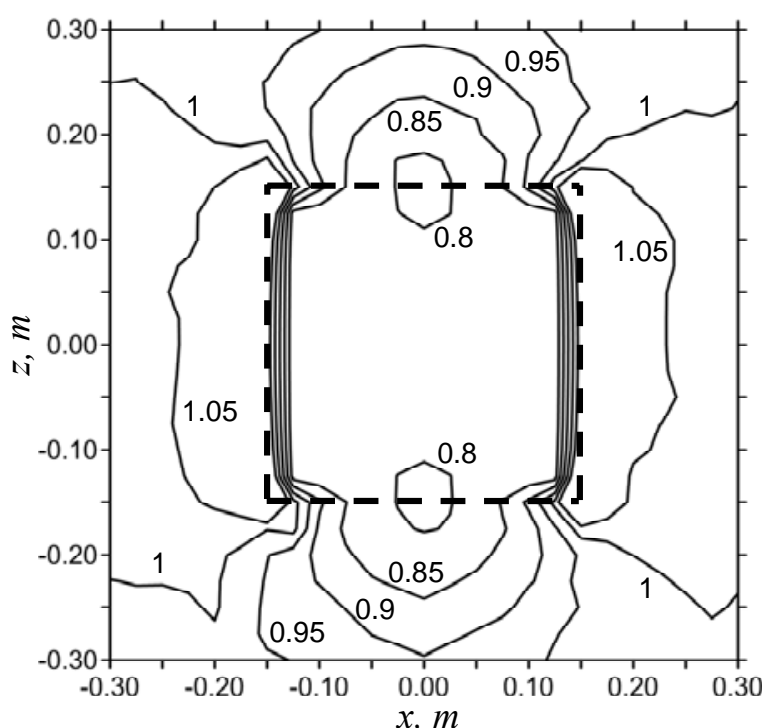

Fig. 2

The comparison of shielding factors for a passive loop and shells. Let's determine the dependence of the shielding factors on the external field frequency for a circular passive loop and conductive shells (spherical and cubic) placed in the homogeneous low-frequency MF. We assume that a passive loop and shells are made from copper with conductivity $\sigma=5.41 \cdot 10^{7} \mathrm{~S} / \mathrm{m}$. The passive loop radius is assumed to be $r_{1}=0.3 \mathrm{~m}$. We consider two cases when the loop's cross-section radius $r_{2}$ equals to $2.5 \mathrm{~mm}$ and $5 \mathrm{~mm}$. Because of the domain of the shielding by the circular passive loop is a sphere of the radius of $r_{1} / 2$ [10], for the comparison of the passive loop's and shells' shielding characteristics let's assume the spherical shell radius $R=r_{1} / 2$ and the cube edge length $a=r_{1}$. Besides, for the correctness of the shielding characteristics comparison, the passive loop's and shells' metal intensities should be the same. Therefore, the spherical shell thickness $d_{s}$ and cubic shell one $d_{c}$ are determined as follows:

$$
\begin{gathered}
d_{s}=2 \pi r_{2}^{2} / r_{1}, \\
d_{c}=\left(\pi r_{2}\right)^{2} /\left(3 r_{1}\right) .
\end{gathered}
$$

In Fig. 3 the shielding factor dependence on the external MF frequency in the case $r_{2}=2.5 \mathrm{~mm}$ is represented. The full line corresponds to $S F_{\text {coil }}$, the dashed line corresponds to $S F_{\text {sphere }}$, and dots correspond to $S F_{\text {cube }}$. The dependences $S F_{\text {coil }}(f)$ and $S F_{\text {sphere }}(f)$ are obtained by using analytical expressions (2) and (4), respectively. The dependence $S F_{\text {cube }}(f)$ is obtained by interpolation of numerical modeling results depicted by dots in Fig. 3 .

From the presented dependences it can be seen that at frequencies less than $f_{0}=217 \mathrm{~Hz}$ the effectiveness of the shielding by the circular passive loop is higher that the effectiveness of the shielding by the spherical shell. From physical point of view, it can be explained by the change of the mechanism of the MF mitigation in the shielded domain. At $f<f_{0}$ the MF mitigation is determined by the inducted conduction current only, but at $f>f_{0}$ it is necessary to take into account the contribution of the MF attenuation in the shell's walls. As it is shown from Fig. 3 at frequencies $200-250 \mathrm{~Hz}$ the shielding factor equals to $1.15-1.20$.

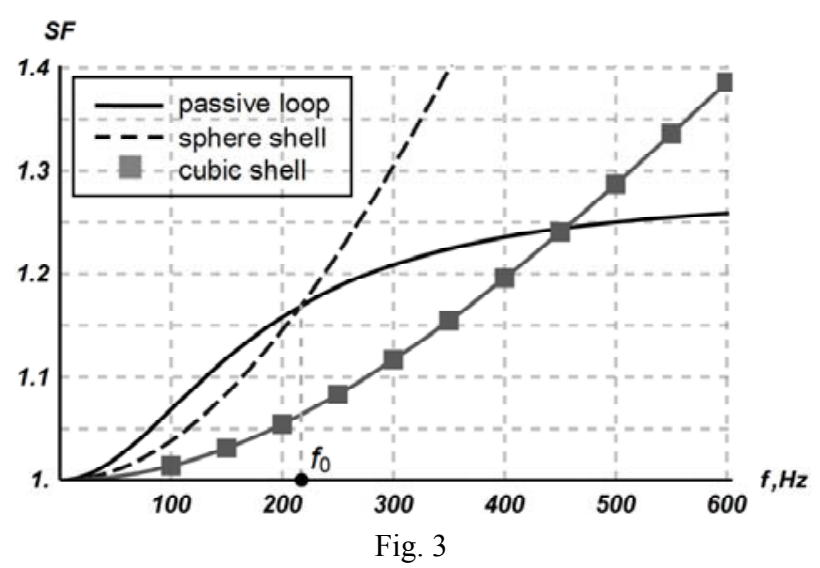

As it was supposed the cubic shell's shielding characteristics are lower in the comparison with spherical one's at all frequency spectrum. In its turn, the cubic shell's shielding characteristics are lower than passive loop's ones at frequencies less than $454 \mathrm{~Hz}$ that is two times greater than $f_{0}$ (see Fig. 3).

In Fig. 4 the shielding factor dependence on the external MF frequency in the case $r_{2}=5 \mathrm{~mm}$ is represented. In this case, $f_{0}$ equals to $56 \mathrm{~Hz}$.

The shielding factor is higher than in the previous case that is explained by the metal intensity increase in four times. However, the curves' character is the same. As it can be seen from Fig. 4 the shielding factor of 1.15-1.20 is reached at frequencies $50-60 \mathrm{~Hz}$.

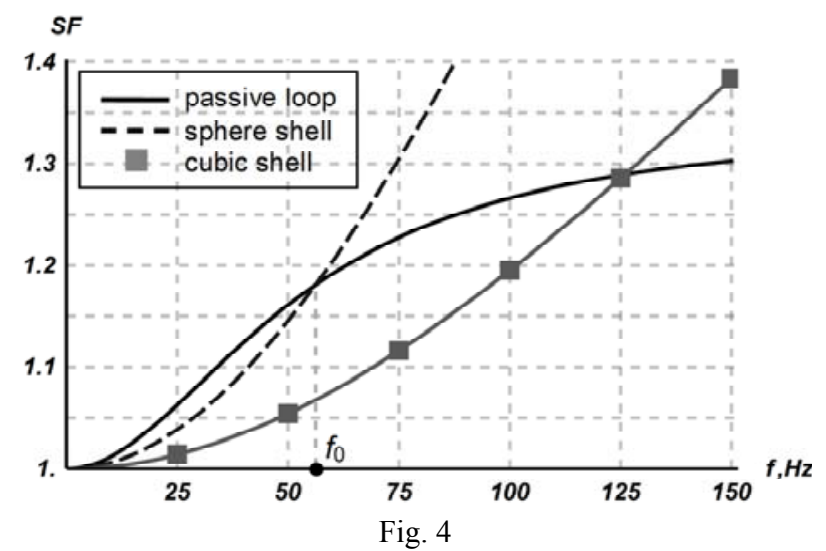

As the shells' metal intensity increases, their walls' thickness increases too. As a result, the penetration depth $\delta$ at which the absorption mechanism becomes prevailing in the MF shielding increases, too. Therefore, as the metal intensity increases the value of the frequency $f_{0}$ decreases. The value of the frequency $f_{0}$ can be obtained analytically from the equation

$$
\left.S F_{\text {coil }}\right|_{f=f_{0}}=\left.S F_{\text {sphere }}\right|_{f=f_{0}} .
$$

Using (2) and (4) we obtain:

$$
\begin{aligned}
& f_{0}=\frac{6}{\mu_{0} \sigma} \cdot \frac{R}{V} \times \\
& \times \frac{\sqrt{-\left(\frac{4}{9}+\frac{16}{125}\right) \cdot \pi^{2}+\frac{8 \pi}{5 \sqrt{5}} \cdot\left(-\frac{7}{4}+\ln (32 \pi)+\frac{1}{2} \ln \frac{R^{3}}{V}\right)}}{-\frac{4 \pi}{5 \sqrt{5}}-\frac{7}{4}+\ln (32 \pi)+\frac{1}{2} \ln \frac{R^{3}}{V}},
\end{aligned}
$$


where $V=2 \pi r_{1} \cdot \pi r_{2}^{2}=4 \pi R^{2} \cdot d_{s}$ is the metal intensity of the circular passive loop and shell; $R$ is the radius of the shielded domain.

Calculating the numerical coefficients with precision till three significant digits, we obtain the final expression for $f_{0}$ :

$$
f_{0}=\frac{12,7}{\mu_{0} \sigma} \cdot \frac{R}{V} \cdot \frac{\sqrt{0,694+\ln \frac{R^{3}}{V}}}{3,47+\ln \frac{R^{3}}{V}} .
$$

So, in the region $f>f_{0}$ in order to mitigate the MF in the region of the radius $R$ at given metal intensity $V$ it is useful to use the closed conductive shell. If the external MF frequency $f<f_{0}$, it is useful to use the circular passive loop with radius $2 R$.

Conclusions.

1. Analytical expressions for shielding factors for the circular passive loop and conductive spherical shell are obtained which together with developed numerical model of the cubic shell permit to compare their effectiveness of the external MF shielding at various frequencies.

2. The external MF frequency $f_{0}$ is determined which can serve as a criterion of the expediency of the circular passive loop utilization. At the MF frequency less than $f_{0}$, the passive loop shielding factor is higher than the shielding factor for the equivalent volume spherical shell. At the MF frequency less than $2 f_{0}$, passive loop shielding factor is higher than the shielding factor for the equivalent volume cubic shell.

\section{REFERENCES}

1. International Commission on Non-Ionizing Radiation Protection. ICNIRP Guidelines for limiting exposure to timevarying electric and magnetic fields $(1 \mathrm{~Hz}-100 \mathrm{kHz})$. Health Physics, 2010, vol.99, no.6, pp. 818-836. doi: 10.1097/HP.0b013e3181f06c86.

2. Korol' E.G., Pantelyat M.G. EMC requirements of technical devices at electric power facilities and industrial. Visnyk $N T U$ «KhPI» - Bulletin of NTU «KhPI», 2013, no.15, pp. 35-60. (Rus)
3. Rozov V.Yu. Assuirov D.A. Method of the active shielding of technical objects external magnetic field. Tekhnichna elektrodynamika - Technical electrodynamics, 2006, no.3, pp. 13-16. (Rus).

4. Kuznetsov B.I., Nikitina T.B., Bovdui I.V., Voloshko A.V., Vinichenko E.V., Kotliarov D.A. Active screening of magnetic field near power station generator buses. Elektrotekhnika i elektromekhanika - Electrical engineering \& electromechanics, 2013, no.6, pp. 66-71. (Rus).

5. Kaden H. Wirbelströme und Schirmung in der Nachrichtentechnik. - Springer Berlin Heidelberg, 1959. doi: 10.1007/978-3-540-32570-3.

6. Buccella C., Feliziani M., Maradei F., Manzi G. Magnetic field computation in a physically large domain with thin metallic shields. IEEE Transactions on Magnetics, 2005, vol.41, no.5, pp. 1708-1711. doi: 10.1109/TMAG.2005.846059.

7. Kistenmacher P., Schwab A. Low-frequency shielding effectiveness of inhomogeneous enclosures. Proceedings of IEEE International Symposium on Electromagnetic Compatibility, 1996, pp. 347-352. doi: 10.1109/ISEMC.1996.561256.

8. Clairmont B.A., Lordan R.J. 3-D modeling of thin conductive sheets for magnetic field shielding: calculations and measurements. IEEE Transactions on Power Delivery, 1999, vol.14, no.4, pp. 1382-1393. doi: 10.1109/PESW.1999.747382.

9. Roginskiy V.Yu. Ekranirovanie $v$ radioustroystvah [Shielding in radio devices]. Leningrad, Energiya Publ., 1969. 112 p. (Rus).

10. Grinchenko V.S., Chunikhin K.V. Shielding of a uniform alternating magnetic field using a circular passive loop. Elektrotekhnika i elektromekhanika - Electrical engineering \& electromechanics, 2015, no.2, pp. 31-34. (Rus).

Received 11.01.2016

V.S. Grinchenko ${ }^{1}$, Candidate of Technical Science,

K.V. Chunikhin ${ }^{1}$,

N.V. Grinchenko ${ }^{2}$, Candidate of Technical Science,

${ }^{1}$ State Institution «Institute of Technical Problems

of Magnetism of the NAS of Ukraine»,

19, Industrialna Str., Kharkiv, 61106, Ukraine,

e-mail: vsgrinchenko@gmail.com,kvchunikhin@gmail.com

${ }^{2}$ Ukrainian State University of Railway Transport,

7, Feuerbach Sq., Kharkiv, 61050, Ukraine. 